Revista de BIOLOGía TROPICAL

\title{
Anatomía Floral de Peristethium leptostachyum (Loranthaceae)
}

\author{
Alejandra Robles ${ }^{1}$, Lauren $\operatorname{Raz}^{2}$ \& Xavier Marquínez ${ }^{1}$ \\ 1. Departamento de Biología, Universidad Nacional de Colombia (sisbio, COL0024669); arobless@unal.edu.co, \\ xmarquinezc@unal.edu.co \\ 2. Instituto de Ciencias Naturales, Universidad Nacional de Colombia; 1raz@unal.edu.co
}

Recibido 10-III-2015. C Corregido 20-VIII-2015. Aceptado 24-IX-2015.

\begin{abstract}
Floral anatomy of Peristethium leptostachyum (Loranthaceae). Peristethium leptostachyum is a hemiparasite species of the family Loranthaceae, distributed in Colombia, Costa Rica, Ecuador, Peru, Venezuela and Panama. Previously treated as Struthanthus leptostachyus, the species was recently transferred to Peristethium together with other species of Cladocolea and Struthanthus. The present research describes the inflorescence and floral morphoanatomy of Peristethium leptostachyum, detailing the structure of the androecium and gynoecium and the processes of microgametogenesis and megagametogenesis, thus allowing comparison with Struthanthus and Cladocolea. Flowering material was collected in February and August 2012, in Santa María, Boyacá, Colombia. Histological sections were prepared and stained with astrablue-fuchsin and floral dissections were performed under a stereomicroscope. Peristethium leptostachyum shares inflorescence characters with Cladocolea (determinate inflorescence, ebracteate terminal flower), but also with Struthanthus (pairs of triads along the axis, deciduous bracts and actinomorphic flowers). The flowers of P. leptostachyum from Santa María are clearly hermaphrodites with androecium and gynoecium fully developed. This observation contradicts the description by Kuijt who reported this species to be dioecious. The androecium was observed to be similar to that of Struthanthus vulgaris, with a glandular tapetum and simultaneous microsporogenesis; in contrast, Cladocolea loniceroides has a periplasmodial tapetum and successive microsporogenesis. The gynoecium of P. leptostachyum, like that of Cladocolea, Struthanthus and Phthirusa, has a unilocular ovary with a mamelon and arquesporial tissue isoriented towards the style, which in turn is solid and amyliferous. Peristethium leptostachyum is similar to Cladocolea loniceroides and differs from Strutanthus vulgaris in presenting multiple embryo sacs and an unlignified pelvis (hipostase). The presence of a solid stylar canal is proposed as a synapomorphy of the tribe Psittacanthinae. Given that P. leptostachyum shares characters with both Cladocolea and Struthanthus generic placement cannot be clearly determined on the basis of anatomical evidence. Phylogenetic studies that include representative species of all three genera are desirable to test hypotheses of monophyly. The sexual system observed here in P. leptostachyum is different from that reported by Kuijt and more studies are needed to identify the factors (geographic, ecological, etc.) that influence this variation. Rev. Biol. Trop. 64 (1): 341-352. Epub 2016 March 01.
\end{abstract}

Key words: Santalales, dioecious, hermaphrodite, hypostase, mamelon, microsporogenesis, Psittacanthinae, glandular tapetum, periplasmodial tapetum.

El orden Santalales, compuesto por 18 familias, 160 géneros y aproximadamente 2200 especies de plantas hemiparásitas u holoparásitas (Mathiasen, Nickrent, Shaw, \& Watson, 2008; Nickrent, Malecot, \& Vidal, 2010), conforma el grupo principal de plantas parásitas de la flora tropical (Dueñas, 2001). La familia Loranthaceae es la más representativa del orden, con alrededor de 73 géneros y 960 especies (Dueñas, 2001; Nickrent et al., 2010).

Loranthaceae se distingue de las familias afines por ser plantas hemiparásitas de raíces y ramas, mediante haustorios primarios y secundarios, y con presencia o ausencia de raíces epicorticales. Las hojas curvinervadas tienen disposición opuesta (raramente 
alterna o verticilada), las inflorescencias son terminales o axilares, dispuestas en espigas, racimos, umbelas o capítulos, siendo la unidad básica generalmente un dicasio. Las flores son bisexuales o unisexuales, de simetría radial o bilateral, con un cáliz reducido (a manera de aro, tubo o diente corto) y una corola gamopétala o coripétala, los estambres son libres o epipétalos. Las anteras son basifijas o dorsifijas con 2 o 4 lóculos. El ovario es ínfero y carece de óvulos diferenciados, en su lugar se desarrolla una estructura denominada mamelón, conformada por una masa indiferenciada de tejidos que contienen el saco embrionario. Los frutos son siempre bayas (Nickrent et al., 2010).

Peristethium leptostachyum (Kunth) Tiegh. forma parte de la tribu Psittacantheae Horan. junto con Aetanthus, Cladocolea, Dendropemon, Desmaria, Ixocactus, Ligaria, Notanthera, Oryctanthus, Oryctina, Panamanthus, Phthirusa, Psittacanthus, Struthanthus, Tripodanthus, Tristerix y Tupeia. La monofilia de la tribu está sustentada por caracteres morfológicos, cariológicos y moleculares (Vidal \& Nickrent, 2008; Nickrent et al., 2010).

El género Peristethium Tiegh. fue propuesto originalmente por Van Thieghem (1895), pero no fue reconocido por investigadores posteriores hasta Kuitj (2012). La especie estudiada aquí, P. leptostachyum, fue descrita originalmente como Loranthus leptostachyus Kunth (1820), que además es el basiónimo de la combinación Struthanthus leptostachyus (Kunth) G. Don (1834).

Cuando Don (1834) realizó la transferencia, Struthanthus había sido recién monografiado por Martius (1830), quién reconoció 25 especies suramericanas definidas por los siguientes caracteres genéricos: inflorescencia como una espiga o racimo conformado por pares de tríadas, las flores bisexuales y las anteras dorsifijas sobre filamentos esbeltos. Eichler (1868) en su tratamiento del género corrigió la diagnosis genérica de Martius, indicando las especies como dioicas, cuyas flores unisexuales presentan remanentes abortados de los órganos del sexo contrario. Además, Eichler agregó nueve especies mesoamericanas y 10 suramericanas al género. Actualmente no existe una monografía de Struthanthus pero se calcula que tiene entre 50 y 75 especies.

Kuijt (1975), en su monografía del género Cladocolea Tiegh., señaló que la delimitación entre este género y Struthanthus es incierta dada la presencia de especies con características intermedias. Estudios filogenéticos recientes confirman esta relación de géneros hermanos (Vidal \& Nickrent, 2008). Actualmente, se reconocen más de 30 especies de Cladocolea (The Plant List, 2013), caracterizadas por sus inflorescencias simples y determinadas, así como la ausencia de bractéolas y anteras sésiles adnadas a los pétalos. La sexualidad de las flores varía dentro de este género.

Kuijt (2012) restableció el género Peristethium Tiegh. incluyendo cuatro especies transferidas de Struthanthus, entre ellas $S$. leptostachyus; cinco provenientes de Cladocolea y cinco nuevas especies descubiertas en los Andes de Colombia, Ecuador y Perú. Con el reciente traslado de la especie Strutanthus reticulatus (Simões, Gomes, \& Barnes, 2014), descrita por Rizzini (1980), el género Peristethium completa 15 especies.

Aunque no se han muestreado especies de Peristethium en análisis filogenéticos, el género se incluye de manera preliminar en la Tribu Psittacantheae, y específicamente en la subtribu Psittacanthinae (Vidal \& Nickrent 2008, Nickrent et al. 2010). Esta subtribu también ha sido denominada "taxa de flores pequeñas del Nuevo Mundo" (Vidal \& Nickrent 2008) y "complejo Struthanthus" (Kuijt, 2012).

El restablecimiento del género Peristethium (sensu Kuijt, 2012) se basó en tres caracteres estructurales: (1) desarrollo de brácteas cartáceas en la base y a lo largo del eje de la inflorescencia que subtienden mónadas y tríadas; las brácteas tienden a ser persistentes en la base de la inflorescencia y caducas a lo largo del eje floral; (2) inflorescencia con una flor solitaria terminal seguida por uno o más pares de mónadas ebracteadas, y (3) presencia de anteras sésiles o casi sésiles, epipétalas, insertas en la mitad superior del pétalo. 
Kuijt (2012) describe los siguientes caracteres diagnósticos reproductivos de P. leptostachyum: una o dos inflorescencias axilares de cerca de $12 \mathrm{~cm}$ de longitud, con pedúnculo de $2 \mathrm{~cm}$, varios entrenudos estériles y algunas lenticelas de color marrón, con $\leq 12$ pares de tríadas sésiles, uno o dos pares de mónadas sésiles y solitarias, y una flor terminal; mónadas y tríadas no hundidas en copas nodales, cada inflorescencia subtendida por numerosos pares de brácteas caducas en estado temprano, brácteas florales y bractéolas caducas; flores hexámeras, unisexuales, no hundidas en copas nodales, botones de 4-5 $\mathrm{mm}$; la flor femenina es esbelta, la flor masculina es ancha y más corta; anteras de la flor masculina sésiles, algunas veces retorcidas, en dos series a alturas ligeramente diferentes por encima de la media de los pétalos, en ocasiones con pelos blancos directamente debajo; anteras en la flor femenina estériles, en forma de correa; estigma capitado, distinto, oblicuo; estilo esencialmente recto, presente también en la flor masculina; fruto de 7 × $5 \mathrm{~mm}$, de forma elipsoidal, de color rojizo inicialmente y al madurar de tonalidad azul oscura.

En especies de algunos géneros de la subtribu Psittacanthinae que son afines a Peristhetium, tales como Cladocolea loniceroides (Cid, 2006), Phthirusa pyrifolia (Kuijt \& Weberling, 1972), Strutanthus vulgaris (Venturelli, 1981, 1984a) y Struthanthus flexicaulis (Venturelli, 1984b), se han realizado estudios de estructura floral y embriología. Estudios similares también se han realizado en géneros algo más distantes, pero pertenecientes a la tribu Psittacantheae, como Psittacanthus (Gómez, Sánchez \& Salazar, 2011), Tripodanthus (Cocucci \& Venturelli, 1982; Venturelli, 1983; Cocucci, 1983) y Tupeia (Smart, 1952). Finalmente, la serie titulada "morphological and embryological studies in the family Loranthaceae", registra estudios en 13 especies de Loranthaceae, mismos que han sido compilados y analizados por Bhatnagar y Johri (1983) y por Cocucci (1983).

En este estudio se describió y analizó la morfología y anatomía de flores e inflorescencias de Peristethium leptostachyum, detallando la estructura del androceo y gineceo, así como los procesos de microgametogénesis y megagametogénesis. También se realizaron comparaciones con especies afines de la tribu Psittacanthinae, buscando caracteres informativos para posteriores estudios taxonómicos y filogenéticos, y para hacer precisiones en relación con las diagnosis previas de la especie, en particular, para definir si es dioica como propone Kuijt, o si es hermafrodita como han señalado otros investigadores.

\section{MATERIALES Y MÉTODOS}

Botones florales, inflorescencias jóvenes y maduras, y flores maduras individuales de Peristethium leptostachyum fueron recolectados en febrero y agosto 2012 en el Municipio de Santa María, localidad Cascada la 70 (456’24.57” N - 73²0’10.69”; Boyacá - Colombia); junto con ejemplares testigo depositados en el Herbario Nacional Colombiano (A. Robles-Sánchez, 001-002 COL). Los micropreparados se encuentran en la colección del Laboratorio 101 del Departamento de Biología, Universidad Nacional de Colombia, sede Bogotá.

La determinación de la planta hasta el nivel de especie fue llevada a cabo utilizando las claves de Kuijt (2012) y confirmado por los expertos Job Kuijt y Daniel L. Nickrent a partir de fotografías de la planta en vivo y a partir de material recolectado, respectivamente. Las muestras recolectadas se fijaron en solución FAA (10:5:85, Formol: ácido acético: EtOH 70 \%) por 48 horas, y posteriormente, se trataron siguiendo los protocolos convencionales de Johansen (1940) modificados así: deshidratación en series de EtOH, $70 \%$ por 24 horas, $90 \%, 96 \%, 100 \%$ y $100 \%$ por 4 horas c/u; series de $\mathrm{EtOH} 100 \%$ y agente aclarante Histoclear $(90: 10,70: 30,50: 50,30: 70,100,100)$; imbibición en parafina (paraplast plus, $60{ }^{\circ} \mathrm{C}$ ) tres veces por 24 horas c/u; secciones seriadas o individuales en micrótomo de rotación (820 Spencer, American Optical Company, NY) y fijación en láminas con aplicación del reactivo de Haupt (Ruzin, 1999). Las láminas se 
colocaron en horno a $60^{\circ} \mathrm{C}$ por 24 horas, luego se desparafinaron mediante dos pasos por xilol $100 \%$, EtOH 50: xilol 50 por 3 minutos (x2), seguido por hidratación en series de EtOH 100 $\%, 95 \%, 70 \%, 50 \%$ y $\mathrm{H}_{2} \mathrm{O}$ destilada por 2 minutos, y tinción con astra-blue acidificado $(1 \mathrm{~g} / 100 \mathrm{~mL}$ de $2 \%$ ácido tartárico) por 10 minutos, seguido por un lavado en $\mathrm{H}_{2} \mathrm{O}$ destilada por 2 minutos, y contratinción con fucsina básica etanólica $(0.1 \mathrm{~g} / 100 \mathrm{~mL}$ de etanol al 50 $\%)$ por 20 minutos, lavado en agua destilada por 15 segundos. Después de la tinción se realizó una deshidratación en series de $\mathrm{EtOH}$ (50 $\%, 70 \%, 95 \%, 100 \%, 100 \%$; 1 minuto c/u), y de etanol: xilol (70:30, 50:50; 2 minutos c/u), xilol $100 \% 2$ veces por 3 minutos. Al final se colocó citoresina sobre los portaobjetos, se montó el cubreobjetos y se dejó secar a temperatura ambiente.

Los micropreparados se analizaron y fotografiaron utilizando microscopios Nikon Eclipse E100 y Olympus BX50 con cámaras AmScope MU300 y Motic Moticam Pro 282B respectivamente, las imágenes digitales se procesaron y editaron con el programa PhotoScape. Los órganos recolectados y fijados se mantuvieron en etanol al $70 \%$. Se realizaron observaciones y mediciones de las inflorescencias y flores con estereoscopio Nikon SMZ745T, tomándose fotografías con una cámara Opticam PRO5. Las imágenes digitales se editaron con el programa PhotoScape.

\section{RESULTADOS}

Inflorescencia: P. leptostachyum presenta inflorescencia en racimo, con una flor terminal solitaria ebracteada (inflorescencia determinada), rodeada por pares de tríadas bracteadas que se distribuyen en forma decusada a lo largo del eje (Fig. 1A); las brácteas que cubren las tríadas en estado de botón floral se caen durante la antesis. Tanto los ejes cortos que sostienen las tríadas, como los pedicelos de las flores son artículados. El desarrollo de las flores en el racimo es acrópeto, esto es, primero abren las tríadas de la base de la inflorescencia, continuando en orden hacia el ápice inflorescencial; todas las flores en antesis son hermafroditas, hexámeras, con cuerpo esbelto y un tamaño de ca. $6.7 \times 1.5 \mathrm{~mm}$ (longitud $\mathrm{x}$ ancho; Fig. 1B y Fig. 1C). Los frutos son bayas de ca. 7 x 5 $\mathrm{mm}$, forma elipsoidal y de tonalidad rojiza a azul oscura.

Los pedicelos son cortos y están recubiertos por una epidermis uniseriada conformada por células cuadrangulares y cutícula delgada; corteza y médula parenquimática sin idioblastos y seis (flor terminal) o siete (flor lateral) haces vasculares dispuestos de forma concéntrica (Fig. 1D). En las flores laterales, uno de los haces inerva las brácteas florales.

Anatómicamente, las brácteas florales en epidermis abaxial y adaxial uniseriadas, formada por células alargadas, sin estomas; un mesófilo indiferenciado compuesto por tres capas de células parenquimáticas redondeadas y un haz vascular de tipo colateral que ramifica (Fig. 1E).

Perianto - cáliz y corola: Dado que el ovario es ínfero, el cáliz de color verde pálido se localiza sobre el ovario a manera de anillo (calículo; Fig. 1F). En sección longitudinal, el cáliz tiene $0.1 \mathrm{~mm}$ de anchura máxima y 0.27 $\mathrm{mm}$ de longitud (Fig. 1C). Las epidermis son uniseriadas, la adaxial con células de recubrimiento pequeñas y alargadas, en tanto que la abaxial con células más grandes y redondeadas (Fig. 1C, Fig. 1F); el mesófilo parenquimático es indiferenciado, con un máximo de 7-8 células en la base y sin vascularización.

La corola tiene seis pétalos (ocasionalmente siete) adnados en un $1 / 3$ de su longitud $(4.2 \times 0.8 \mathrm{~mm})$, de color blanco amarillento (Fig. 1A, Fig. 1B, Fig. 1C); la base que une el anillo gamopétalo con el receptáculo floral es delgada (articulada; Fig. 1C), seguida de una zona amplia que incluye los pétalos y estambres adnados en el tercio basal (Fig. 1C); los dos tercios terminales corresponden a la lámina libre de los pétalos.

Epidermis uniseriada abaxial conformada por células de recubrimiento redondeadas, con cutícula delgada y epidermis adaxial con células más cuadradas, pero de un tamaño similar; 

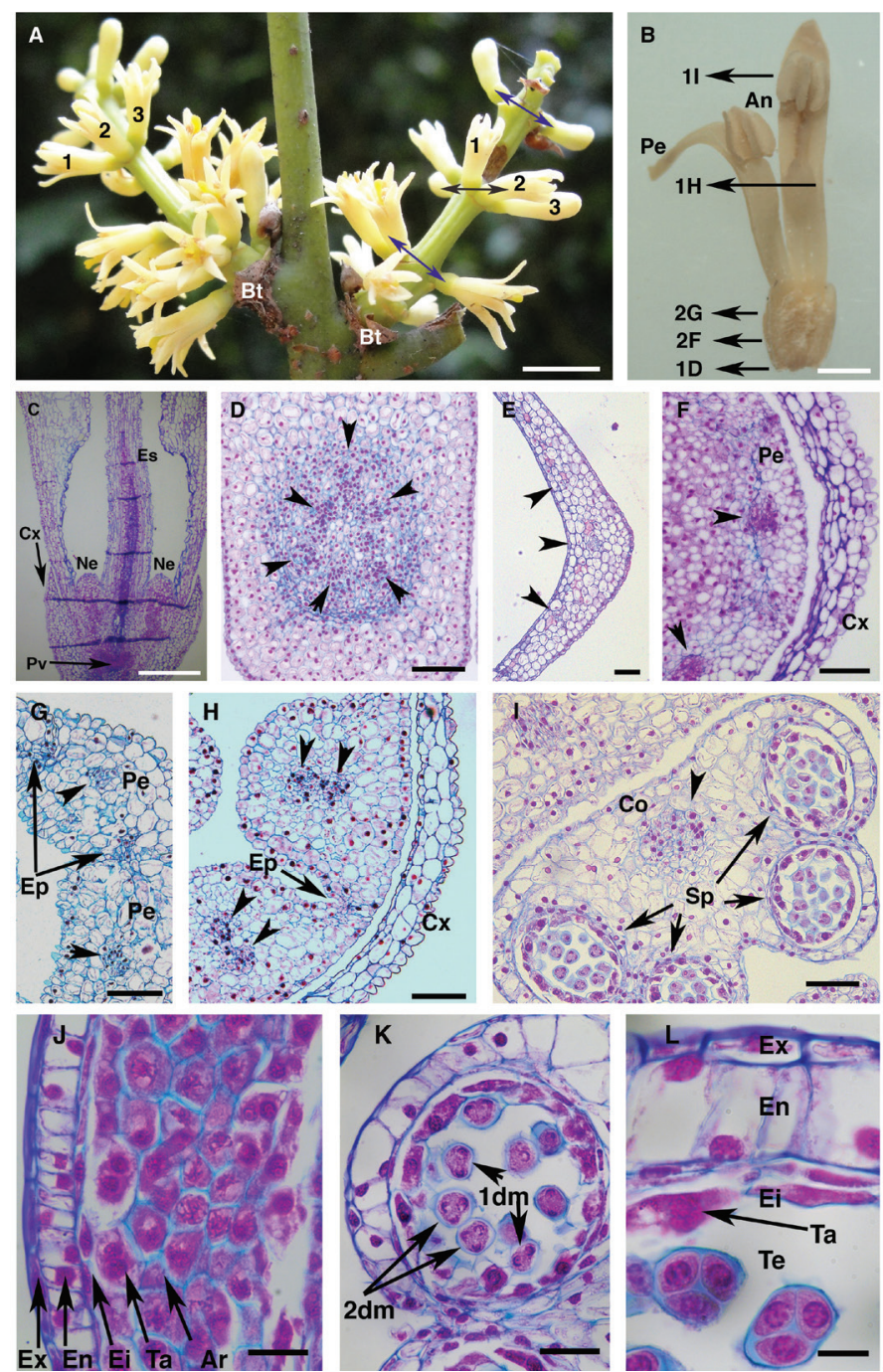

Fig. 1. A. Inflorescencia de Peristethium leptostachyum con flores en desarrollo acrópeto; B. Flor individual en vista longitudinal (las flechas indican la posición aproximada de las secciones transversales correspondientes a las figuras $1 \mathrm{D}, 1 \mathrm{H}$, 1I, 2F y 2G; C. Sección longitudinal de la flor, D. pedúnculo floral; E. Bráctea floral; F. Cáliz y pétalos; G. Pétalos; H. Cáliz y sépalos a nivel de la base de los filamentos; I. Antera joven con arquesporio; J. Detalle de saco polínico de antera joven; $\mathbf{K}$. antera con microsporas en primera y segunda división meiótica; $\mathbf{L}$. Antera con tétradas. $\mathbf{1 , 2 , 3}=$ flores en tríadas, $\mathbf{1 d m}=$ primera división meiótica, $\mathbf{2 d m}=$ segunda división meiótica, $\mathbf{A n}=$ antera, $\mathbf{A r}=$ arquesporio, $\mathbf{B t}=$ bráctea, $\mathbf{C x}=$ cáliz, $\mathbf{C o}=$ conectivo, Ei = estratos intermedios, $\mathbf{E n}=$ endotecio, $\mathbf{E p}=$ células epidérmicas unidas por interdigitación; $\mathbf{E s}=$ estilo, $\mathbf{E x}$ $=$ exotecio, $\mathbf{N e}=$ nectario, $\mathbf{P e}=$ pétalo, $\mathbf{P v}=$ pelvis, $\mathbf{S p}=$ sacos polínicos, $\mathbf{T a}=$ tapetum, $\mathbf{T e}=$ tétradas. Cabezas de flecha = haces vasculares. C-L. Microscopía óptica, safranina verde rápido. C,J: Secciones longitudinales: D-I, K,L. Secciones transversales. Escalas: $5 \mathrm{~mm}$ en A; $1 \mathrm{~mm}$ en B; $500 \mu \mathrm{m}$ en $\mathbf{C} ; 200 \mu \mathrm{m}$ en D-I; $100 \mu \mathrm{m}$ en J,K; $50 \mu \mathrm{m}$ en $\mathbf{L}$.

Fig. 1. A. Peristethium leptostachyum inflorescence with flowers developing acropetally; B. Single flower in longitudinal view (arrows indicate the approximate position of the corresponding cross sections to $1 \mathrm{D}, 1 \mathrm{H}, 1 \mathrm{I}, 2 \mathrm{~F}$ and $2 \mathrm{G}$; C. Longitudinal section of the flower; D. Flower peduncle; E. floral bract; F. calyx and petals; G. petals; H. Calyx and sepals at the base of the filaments; I. Young anther with archaesporium; J. Detail of young anther pollen sac; K. anthers with microspores in the first and second meiotic divisions; $\mathbf{L}$. Anther with tetrads. 1,2,3 = triad of flowers, $\mathbf{1 d m}=$ first meiotic division, $\mathbf{2 d m}=$ second meiotic division, $\mathbf{A n}=$ anther, $\mathbf{A r}=$ archaesporium, $\mathbf{B t}=$ bract, $\mathbf{C x}=$ calyx, $\mathbf{C o}=$ connective, $\mathbf{E i}=$ intermediate strata, $\mathbf{E n}=$ endothecium, $\mathbf{E p}=$ epidermal cells connected by interdigitation; $\mathbf{E s}=$ style, $\mathbf{E x}=$ exothecium, $\mathbf{N e}=$ nectary, $\mathbf{P e}=$ petal, $\mathbf{P v}=$ pelvis, $\mathbf{S p}=$ pollen sacs, $\mathbf{T a}=$ tapetum, $\mathbf{T e}=$ tetrads. Arrow heads $=$ vascular bundles. $\mathbf{C}-\mathbf{L}$ : Optical microscopy, fast green-safranin. C,J: Longitudinal sections: DI,K,L. Cross sections. Scales: $5 \mathrm{~mm}$ in A; $1 \mathrm{~mm}$ en B; $500 \mu \mathrm{m}$ in C; $200 \mu \mathrm{m}$ in D-I; $100 \mu \mathrm{m}$ in $\mathbf{J}, \mathbf{K} ; 50 \mu \mathrm{m}$ in $\mathbf{L}$. 
mesófilo de 7 a 8 células de grosor, homogéneo y conformado por células parenquimáticas, forma casi cuadrangular y consistencia robusta y un solo haz vascular central inmerso, con xilema central y floema periférico. En los botones florales, los pétalos están unidos entre sí por interdigitación de las células epidérmicas externas excepto en el extremo distal donde su separación permite identificar el inicio de la abertura floral (Fig. 1G, Fig. 1H y Fig. 2K).

Androceo y microsporogénesis: El androceo está conformado por seis estambres epipétalos, tres con filamentos largos $(1.3 \mathrm{~mm}) \mathrm{y}$ tres con filamentos cortos (1 mm), intercalados entre sí; en los dos casos, la base del filamento es amplia, de cerca de $0.6 \mathrm{~mm}$ en el sitio de inserción y de $0.2 \mathrm{~mm}$ en el centro. El único haz vascular de cada pétalo ramifica y se introduce en el filamento de la antera proporcionando vascularización al estambre correspondiente (Fig. 1H). El filamento de la antera presenta epidermis uniseriada, de células cuadrangulares, corteza parenquimática, conformada por células redondeadas y un haz vascular central. El conectivo es anatómicamente similar al filamento (Fig. 1H, Fig. 1I).

Las anteras son dorsifijas, bitecas, de 1 $\mathrm{mm}$ de longitud y $0.6 \mathrm{~mm}$ de ancho. En cada teca se ubican dos sacos polínicos de tamaño similar (Fig. 1I). El exotecio es uniseriado, con células de paredes muy delgadas, sin engrosamientos lignificados, con un grosor $10 \mu \mathrm{m}$ y un largo no mayor a $50 \mu \mathrm{m}$. El endotecio está conformado por células grandes, de aspecto cuadrangular y uniseriado, con engrosamientos lignificados en forma de malla, esto es, con las paredes externas, internas y laterales engrosadas, lo cual es especialmente visible en las anteras maduras y dehiscentes (Fig. 2A). Los estratos intermedios están reducidos a una sola capa celular, delgada y alargada. Durante el desarrollo no se acumulan reservas de almidón en ninguna de las capas de la antera (Fig. 1I, Fig. 1J, Fig. 1K y Fig. 1L, Fig. 2A).

El tapetum es secretor y está compuesto por células cuadrangulares, robustas y binucleadas que rodean al tejido esporógeno desde que es arquesporial hasta que finaliza la meiosis (Fig. 1I, Fig. J, Fig. 1K); una vez conformadas las tétradas, el tapetum y los estratos intermedios se degradan (Fig. 1L y Fig. 2A). Durante el proceso de desarrollo se forman orbículas (Corpusculos de Ubisch), pequeñas pero visibles. La dehiscencia de las anteras es de tipo longitudinal y ocurre por deshidratación de los tejidos que generan ruptura por tensión del tabique entre los sacos polínicos de cada teca y a lo largo de las células del estomio (Fig. 2A). Las células del exotecio cercanas al estomio se alargan al final del desarrollo de la antera para facilitar la dispersión del polen.

Las células madre de los granos de polen que conforman el arquesporio son redondeadas, con núcleos prominentes y citoplasma denso, con paredes lisas conformadas principalmente por calosa (Fig. 1I y Fig. 1J), las células madre permanecen laxamente unidas durante el proceso de microsporogénesis (primera y segunda división meiótica; Fig 1K); generándose al final del proceso tétradas tetrahédricas (raramente decusadas) por división simultánea con conformación de paredes lisas de manera centrípeta (Fig. 1L). Las microsporas resultantes son ovoidales. Solamente cuando se rompe la pared de la célula madre son liberadas y comienza la formación de exina e intina; adquiriendo la morfología definitiva de los grano de polen, de un tamaño de ca. $20 \mu \mathrm{m}$, tricolpados, de forma triangular con tres pequeños brazos recorrido por un surco mediano, de simetría isopolar, superficie psilada, algunos ligeramente cóncavos; binucleados (núcleos vegetativo y generativo) al final de su desarrollo al interior de la antera (Fig. 2A y Fig. 2B).

Vascularización floral, gineceo y megasporogénesis: Antes de describir la estructura del gineceo (ovario infero), conviene describir la vascularización floral. El pedicelo tiene 6 haces vasculares, excepcionalmente 7 (Fig. 1D). A la altura de la pelvis (Fig. 2C), estructura sobre la que se desarrolla el ovario, estos seis haces vasculares quedan en posición externa (Fig. 2D, Fig. 2E), recorren el hipanto e inervan los pétalos, bifurcando nuevamente 

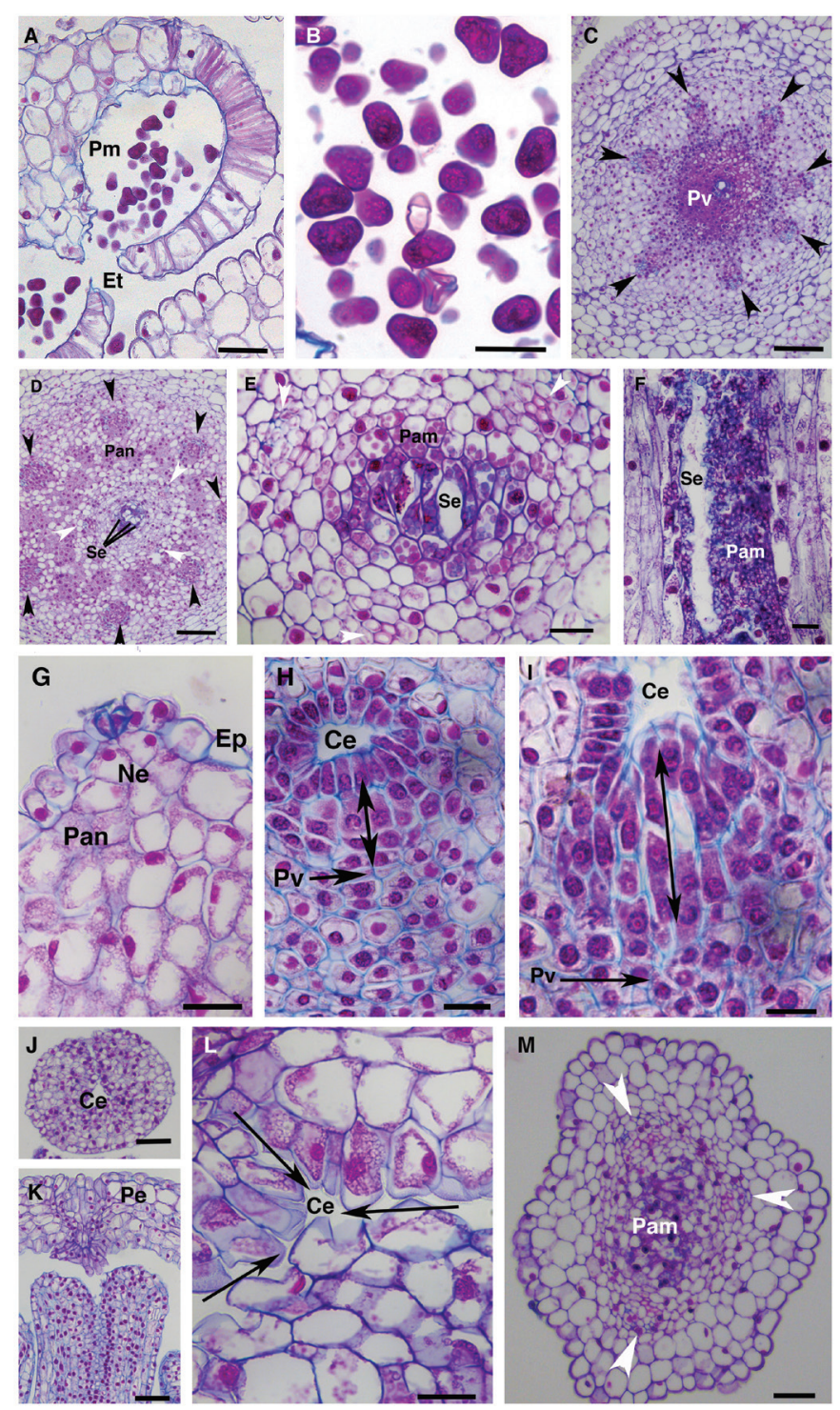

Fig. 2. A. antera madura dehiscente; B. polen maduro; C. sección transversal de ovario a nivel de la pélvis; D. sección transversal del ovario a nivel de los sacos embrionarios; E-F. detalle de saco embrionario inmerso en parenquima amilifero; G. nectario; H. mamelón con diadas (doble flecha); I. mamelón con tétradas (doble flecha); J-K. estigma de flor en botón; L. Detalle de la sutura del estigma en flor en botón; M. estigma de flor en antesis. $\mathbf{C e}=$ canal del estilo, $\mathbf{E p}=$ epidermis, $\mathbf{E t}$ = estomio, $\mathbf{P m}=$ polen maduro, $\mathbf{P v}=$ pelvis, $\mathbf{P a m}=$ parénquima amilífero del mamelón, $\mathbf{P a n}=$ parénquima amilífero del nectario, $\mathbf{P e}=$ pétalos, $\mathbf{S e}=$ saco embrionario, Cabezas de flecha blancas $=$ haces vasculares del mamelón, Cabezas de flecha negras: haces vasculares del hipanto. Coloración: safranina verde rápido. F-I, K: Secciones longitudinales; A-E, J, L,M: Secciones transversales. Escalas: $200 \mu \mathrm{m}$ en $\mathbf{C , D}, \mathbf{J}-\mathbf{L} ; 100 \mu \mathrm{m}$ en $\mathbf{A , E}-\mathbf{H}, \mathbf{M} ; 50 \mu \mathrm{m}$ en $\mathbf{B}$.

Fig. 2. A. Mature anther in dehiscence; B. mature pollen; C. ovary cross section at the level of the pelvis; D. ovary cross section at the level of embryo sacs; E-F. detail of embryo sac immersed in starchy parenchyma; G. nectary; H. mamelon with dyads (double arrow); I. mamelon with tetrads (double arrow); J-K. stigma of flower in bud; L. Detail of suture in the stigma of flower in bud; M. stigma of flower at anthesis. $\mathbf{C e}=$ style canal, $\mathbf{E p}=$ epidermis, $\mathbf{E t}=$ stomium, $\mathbf{P m}=$ mature pollen, $\mathbf{P v}=$ pelvis, $\mathbf{P a m}=$ starchy parenchyma of the mamelon, $\mathrm{Pan}=$ starchy parenchyma of the nectary, $\mathbf{P e}=$ petals, Se $=$ embryo sac, white arrow heads = vascular bundles of the mamelon, black arrow heads: vascular strands of the hypanthium. Colouring: safranin fast green. F-I, K: Longitudinal sections; A-E, J, L, M: Cross sections. Scales: $200 \mu \mathrm{m}$ en $\mathbf{C , D , J - L ; ~} 100 \mu \mathrm{m}$ en $\mathbf{A}, \mathbf{E}-\mathbf{H}, \mathbf{M} ; 50 \mu \mathrm{m}$ en $\mathbf{B}$. 
para alimentar las anteras (Fig. 1H). En tanto que tres haces vasculares desconectados de los del receptáculo (Fig. 2D, Fig. 2E) se localizan alrededor del mamelón y continúan a lo largo del pistilo, rodeando el tejido de transmisión central, hasta la base del estigma.

El receptáculo floral esta recubierto por una epidermis uniseriada y un tejido parenquimático conformado por células parenquimáticas grandes y redondeadas (8 a 12 capas, con células en división periclinal), seguido por células parenquimáticas más pequeñas y alargadas periclinalmente (6-7 capas) que rodean a los seis haces conductores colaterales abiertos, separados por radios parenquimáticos de una a cinco células de grosor y rodeando una médula parenquimática de 4-6 células de diámetro (Fig. 1D).

El receptáculo conforma una estructura en forma de copa (hipanto) que rodea al ovario, el cual se localiza sobre la pelvis (Fig. 1C y Fig. 2C); el hipanto presenta una zona externa, con células parenquimáticas muy vacuoladas que incluye los seis haces vasculares y que culmina en los pétalos, y una zona interna a los haces conformada por parénquima de citoplasma más denso y abundantes amiloplastos que culmina en el anillo nectarífero que rodea al estilo (Fig. 2D); en sección longitudinal se observan estomas apicales rematando el anillo nectarífero (Fig. 2G).

En el centro de la flor y por encima de la pelvis, manteniendo continuidad histológica con el hipanto, se encuentra el ovario, alimentado por tres haces que lo recorren externamente (Fig. 2D y Fig. 2E) y continúan en el estilo. El ovario es una estructura de tipo mamelón sensu Brown, Nickrent y Gasser (2010) u "ovario colectivo" (sensu Venturelli, 1984a), esto significa que los megagametofitos (sacos embrionarios) se desarrollan directamente de una estructura ginecial central sin la formación de óvulos (Fig. 2D, Fig. 2E).

Al inicio del desarrollo, el mamelón se observa como una masa ovoidal de células meristemáticas, mayores que el parénquima circundante y en división activa (ver pares de núcleos, Fig. 2H), localizada por debajo del canal del estilo. El mamelón presenta inicialmente una epidermis y una línea de 4-6 células subepidérmicas arquesporiales, las cuales se alargan y dividen meióticamente dando lugar a díadas y luego tétradas lineales (Fig. 2I). La hipostasa (sensu Johri \& Raj, 1969) o pelvis (sensu Venturelli, 1984a), está conformada por células de paredes engrosadas (Fig. 1C y Fig. 2C, Fig. 2H, Fig. 2I) y se localiza hacia la base del arquesporio, separado de este por dos o tres capas de células.

En la flor en antesis, el mamelón se ha transformado en una estructura alargada, bordeada por los tres haces vasculares y conformada por un parénquima amilífero con una fuerte tinción azul, rodeando a los sacos embrionarios (2-4) que se localizan desde la pelvis hasta la base del estilo (Fig. 1C, Fig. 2I). El parénquima amilífero continúa en el estilo conformando el tejido de transmisión (Fig. 1C, Fig. 2M).

Estilo y estigma: En las fases iniciales de la ontogenia del estilo-estigma se observa una estructura trímera que se fusiona por interdigitación epidérmica, conformando inicialmente un estilo hueco que tiene continuidad hasta el mamelón (Fig. 2J, Fig. 2K, Fig. 2L). En la flor en antesis, el estilo es grueso $(0.3 \mathrm{~mm}$ en la base y $0.4 \mathrm{~mm}$ en el centro) y está conformado por una epidermis uniseriada, con células cuadrangulares, un tejido parenquimático externo formado por células irregulares, tres haces vasculares y un tejido parenquimático de transmisión central sólido con abundantes amiloplastos (Fig. 2M). El estigma es capitado, con un grosor de $0.45 \mathrm{~mm}$, con una epidermis uniseriada de células redondeadas pero no glandulares y sin cutícula evidente (Fig. 2K).

\section{DISCUSIÓN}

Entre las características morfológicas propuestas por Kuijt (2012) para la circunscripción de las especies al interior del complejo Struthanthus se encuentran caracteres como: Inflorescencias determinadas o indeterminadas, unidades en las inflorescencias de tipo mónadas o tríadas, presencia o no de bracteolas en 
las mónadas, y presencia (en Peristethium) o ausencia (en los demás géneros) de brácteas cartáceas basales a la inflorescencia.

Los estados de carácter propuestos para Peristhetium (Kuijt, 2012) están presentes en $P$. leptostachyum, donde la inflorescencia es determinada, conformada por una flor terminal (mónada) ebracteada y seguida de tríadas bracteadas; sin embargo, es claro que el desarrollo floral es acrópeto a diferencia de la condición basípeta indicada por Kuijt (2012) para la especie. La estructura inflorescencial es más afín a la de Cladocolea, por ser determinada y conformada por mónadas ebracteadas (Cid, 2006); y difiere de la de Struthanthus spp., que es indeterminada y conformada por tríadas con todas las flores bracteadas (Venturelli, 1981, 1984a, 1984b). Comparte no obstante con Struthanthus vulgaris (Venturelli, 1984a) la presencia de pares de tríadas a lo largo del eje floral, con brácteas caducas y flores actinomorfas.

Entre las interpretaciones de la estructura floral de P. leptostachyum de Kuijt (2012) y el presente estudio se presentan diferencias importantes. Kuijt (2012) describe la especie como dioica; las flores masculinas como cortas y robustas, con tricomas cortos en la base de los filamentos de las seis anteras sésiles, siendo tres de ellas largas estériles y tres cortas viables; y las flores femeninas largas, esbeltas y con anteras estériles. En este trabajo todas las flores observadas fueron hermafroditas, del mismo tamaño y aspecto, y con androceo y gineceo funcional. Las anteras no son sésiles, sino adnadas a los pétalos.

En este trabajo todas las flores observadas fueron del mismo tamaño y aspecto, hermafroditas, con desarrollo de polen viable en todas las anteras (cortas y largas) de acuerdo con la forma y características descritas por Feuer \& Kuijt (1985) y Kuijt (2012); así como con desarrollo del mamelón típico y posteriormente, de sacos embrionarios viables, y con estilo funcional, muy desarrollado y con tres haces vasculares. Las anteras observadas no son sésiles, sino adnadas a los pétalos y con tricomas en la parte inferior.
Aunque Kuijt (2012) señala que el género Peristethium tiene especies dioicas y monoicas con flores hermafroditas, siendo en algunos casos incierta la asignación por material insuficiente en las colecciones; en la descripción de Peristethium leptostachyum, basada en más de 30 especímenes, señala a la especie como dioica con flores unisexuales. Van Tieghem (1895) y Engler (1897) señalaron a esta especie como bisexual. Dado que las condiciones bisexual y dioica se dan en poblaciones diferentes de la especie $P$. leptostachyum, no descartamos la posibilidad que exista variación interespecífica en el sistema reproductivo, y de ser este el caso, el fenómeno requiere más estudio. Se resalta la importancia del uso de varias líneas de evidencia morfológica y anatómica para confirmar la sexualidad en esta y otras especies.

El calículo (cáliz reducido) de Peristethium leptostachyum es anular y carece de vascularización, condición típica de la familia Loranthaceae, excepto de los géneros basales donde si se presentan tejidos vasculares (Kuijt, 2013), anatómicamente se asemeja a Psittacanthus en la ausencia de tricomas, drusas y esclereidas en el cáliz (Gómez et al., 2011).

Kuijt (2013; cf. cuadro 1) al comparar los géneros del complejo Struthanthus, considera el caracter número de pétalos, que en las especies de Peristethium suele variar entre cuatro y seis. La presencia de corola hexa o heptámera encontrada en este trabajo en flores de un mismo individuo de Peristethium leptostachyum genera dudas sobre la utilidad taxonómica de este carácter; el número variable e impar de pétalos monomórficos se contrapone a la idea de corola biseriada propuesta por Wanntorp y De Craene (2009) y apoya el concepto clásico de corola monoseriada defendido por Kuijt (2013). La interdigitación de la epidermis de los pétalos en botón floral es compartida con Struthanthus vulgaris (Venturelli, 1984a).

La vascularización de la flor de Cladocolea loniceroides, P. leptostachyum y Struthantus vulgaris (Venturelli, 1984a) es similar, difiriendo únicamente en el número de haces que recorren el estilo; presentándose tres haces vasculares en las dos primeras especies, en 


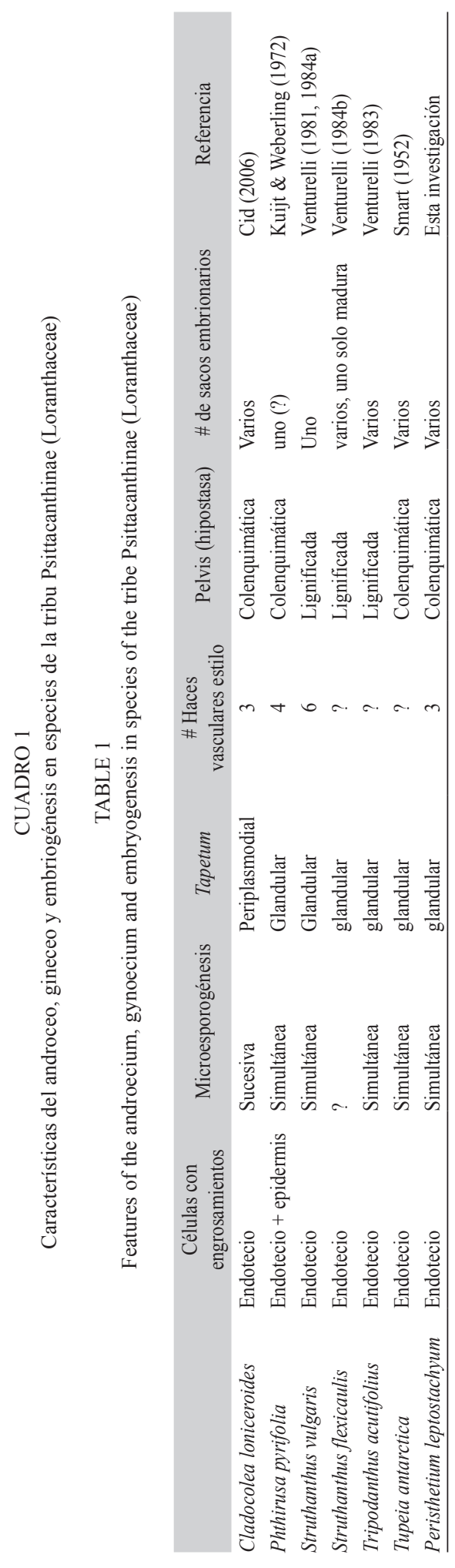

lugar de seis en S. vulgaris, recorriendo el gineceo y el estilo de la flor. En todas estas especies, los haces vasculares que rodean al mamelón propiamente dicho y recorren el estilo $(\mathrm{Hm})$ no están unidas a la vascularización principal de la flor, al menos hasta el momento de la antesis. Dado que el gineceo contiene tres haces vasculares y el estigma en las fases iniciales revela tres lóbulos que se fusionan, se propone como hipótesis que el ovario de $P$. leptostachyum deriva, por reducción, de un ovario tricarpelar.

Peristethium leptostachyum resulta más afín a Struthantus vulgaris debido al tapetum glandular y la microsporogénesis simultánea (Venturelli, 1984a) difiriendo de Cladocolea loniceroides quien presenta tapetum periplasmodial (ameboidal) y microsporogénesis sucesiva (Cid, 2006).

Con la circunscripción de especies propuesta por Nickrent et al. (2010), el gineceo en la tribu Psittacantheae tendría tres condiciones diferentes:

- Tupeia antarctica (subtribu Tupeinae; Smart, 1952) presenta una estructura muy simple, sin óvulo ni mamelón y con el tejido arquesporial debajo de un tejido amilífero sólido que recorre estilo y estigma, que se asemeja a los tipos extremos de reducción encontrados en Helixanthera y Moquiniella (Bhatnagar \& Johri, 1983), con la diferencia de que estos tienen canal estilar abierto.

- Tripodanthus acutifolius, el género más tempranamente divergente (Vidal \& Nickrent, 2008), de la subtribu Psittacanthinae, presenta un ovario trilocular con un compitum abierto que conecta las tres cavidades, con óvulos discretos, mamelón libre, sin integumento, pero con una nucela o megasporangio bien diferenciado y con la región placental superior, de tal manera que el tejido arquesporial está en el polo opuesto al estilo; el canal estilar es cerrado y con tejido amilífero (Venturelli, 1983; cf. Fig. 2 de Cocucci, 1983); todas estas características hicieron que Cocucci 
(1982) lo propusiera equivocadamente como afín a Nuytsia y basal en la familia.

- Cladocolea (Cid, 2006), Phthirusa (Kuijt \& Weberling, 1972), Struthanthus (Venturelli, 1981, 1984a, 1984b) y Peristhethium (esta investigación), presentan un gineceo unilocular, con mamelón cuyo tejido arquesporial se orienta hacia el estilo, el cual es sólido y con tejido amilífero; asemejándose al observado en Helicanthes, Amyema y otros géneros de la tribu Lorantheae (Bhatnagar \& Johri, 1983).

Las propuestas clásicas de evolución del gineceo en Loranthaceae, (Cocucci, 1982; Bhatnagar \& Johri, 1983), y particularmente de la tribu Psittacantheae deben ser revisadas a la luz de la filogenia de Nickrent et al. (2010); no obstante, se propone como sinapomorfía para la tribu, la presencia de un canal estilar sólido cuando la flor esta en antesis; adicionalmente se considera la condición alternativa, canal estilar abierto, como plesiomórfica en la familia, pues en Peristethium se observa en la ontogenia temprana de la flor (cf. Fig. 2J, Fig. 2K, Fig. 2L, Fig. 2M). En la tabla 1 se comparan algunas otras características del androceo, gineceo y embriogénesis en las especies de la tribu Psittacanthinae.

A manera de conclusión, dado que P. Leptostachyum comparte caracteres reproductivos tanto con Cladocolea como con Struthanthus, su relación con estos géneros no queda resuelta en base a la evidencia anatómica. Se requieren estudios filogenéticos que incluyan especies representativas de los tres géneros para evaluar las hipótesis de monofilia. El sistema sexual observado en esta investigación difiere del reportado por Kuijt, por lo que se requieren estudios para identificar los factores geográficos o ecológicos que influencian dicha variación.

\section{AGRADECIMIENTOS}

A Daniel Nickrent y Job Kuijt por confirmar la determinación de la especie P. leptostachyum. A los pobladores del Municipio de
Santa María - Boyacá y al personal de A.E.S. Chivor por la ayuda durante la fase de campo.

\section{RESUMEN}

Peristethium leptostachyum es una especie hemiparásita de la familia Loranthaceae, distribuida en Colombia, Costa Rica, Ecuador, Perú, Venezuela y Panamá. Previamente tratada como Struthanthus leptostachyus, la especie fue recientemente fue reubicada en Peristethium junto con otras que previamente estaban en los géneros Cladocolea y Struthanthus. La decisión de reconocer a Peristethium como género es controversial y fue tomada con base en caracteres de la inflorescencia y de la flor; en tanto que la monofilia de los tres géneros nombrados es incierta. En esta investigación se estudió la morfoanatomía de flores e inflorescencias de Peristethium leptostachyum, detallando la estructura del androceo y gineceo, así como los procesos de microgametogénesis y megagametogénesis; adicionalmente se realizaron comparaciones con especies afines y precisiones en relación con las diagnosis previas. Se recolectaron flores en diversas fases de desarrollo en Santa María (Boyacá-Colombia), se prepararon y analizaron bajo microscopio secciones histológicas teñidas con astrabluefucsina, además de disecciones bajo estereomicroscopio. Los resultados mostraron que P. leptostachyum comparte caracteres inflorenciales con Cladocolea (inflorescencia determinada, flor terminal ebracteada), pero también con Struthanthus (pares de tríadas a lo largo del eje, brácteas caducas y flores actinomorfas). Las flores de P. Leptostachyum de Santa María son claramente hermafroditas, con androceos y gineceos totalmente desarrollados; lo cual contradice la descripción hecha por Kuijt que reporta una condición dioica para esta especie. El androceo resultó afín al de Struthanthus vulgaris, con tapetum glandular y microsporogénesis simultánea; en contraste, Cladocolea loniceroides presenta tapetum periplasmodial y microesporogénesis sucesiva. El gineceo de P. leptostachyum, al igual que en Cladocolea, Struthanthus y Phthirusa, es unilocular con mamelón y tejido arquesporial orientado hacia el estilo, el cual es sólido y con tejido amilífero. P. leptostachyum es afín a Cladocolea loniceroides y difiere de Struthanthus vulgaris por presentar varios sacos embrionarios y pelvis (hipostasa) no lignificada. La presencia de un canal estilar sólido se propone como sinapomorfía de la tribu Psittacanthinae. Dado que $P$. Leptostachyum comparte caracteres anatómicos florales tanto con Cladocolea como con Strutanthus, la relación entre estos tres géneros no queda resuelta, se requieren estudios filogenéticos para establecer esta relación y poner a prueba las hipótesis de monofilia de cada uno de ellos.

Palabras clave: Santalales, dioica, hermafrodita, hipostasa, mamelón, microesporogénesis, psittacanthinae, tapetum glandular, tapetum periplasmodial. 


\section{REFERENCIAS}

Bhatnagar, S. P., \& Johri, B. M. 1983. Embryology of Loranthaceae. In M. Calder, \& P. Bernhardt, (Eds.). The biology of mistletoes (pp. 47-66). London: Academic Press.

Brown, R., Nickrent, D., \& Gasser, C. (2010). Expression of the ovule and integument-associated genes in reduced ovules of Santalales. Evolution \& Development, 12, 231-240.

Cid, R. M. (2006). Biología del desarrollo de Cladocolea loniceroides (Van Tieghem) Kuijt, Loranthaceae (Tesis de Doctorado). Universidad Nacional Autónoma de México. México, DF, México.

Cocucci, A. E., \& Venturelli, M. (1982). El ovulo y el gineceo en Loranthaceae. Boletín de la Sociedad Argentina de Botánica, 21(1-4), 131-141.

Cocucci, A. E. (1983). New evidence from embryology in angiosperm classification. Nordic Journal of Botany, $3,67-73$.

Don, G. (1834). A General System of Gardening and Botany (vol. 3, p. 411). London: C.J.G. and F. Rivington.

Dueñas, H. (2001). Sinopsis de las Loranthaceae de Colombia. Caldasia, 23, 81-99.

Eichler, A. W. 1868. Loranthaceae. In K. F. P. Martius (Ed.). Flora Brasiliensis (Vol. 5, part 2, pp. 1-136). Leipzig: F. Fleischer.

Engler, A. (1897). Loranthaceae. In A. Engler, \& K. Prantl (Eds.), Die Natürlichen Pflanzenfamilien, Nachträge zum II-IV Teil (pp. 124-140). Leipzig: W. Engelmann.

Feuer, M., \& Kuijt, J. (1985). Fine Structure of Mistletoe Pollen VI. Small-Flowered Neotropical Loranthaceae. Annals of the Missouri Botanical Garden, 72, 187-212.

Johansen, D. J. (1940). Plant Microtechnique. New York: McGraw-Hill Book.

Johri, B. M., \& Raj, B. (1969). Morphological and Embryological Studies in the Family Loranthaceae. XII. Moquiniella rubra (Spreng. f.) Balle. Österreichische Botanische Zei, 116, 475-485.

Gómez, M., Sánchez, L., \& Salazar, L. (2011). Anatomía de especies mexicanas de los géneros Phoradendron y Psittacanthus, endémicos del Nuevo Mundo. Revista Mexicana de Biodiversidad, 82, 1203-1218.

Kuijt, J., \& Weberling, F. (1972). The flower of Phthirusa pyrifolia (Loranthaceae). Berichte der Deutschen Botanischen Gesellschaft, 85, 467-480.

Kuijt, J. (1975). The genus Cladocolea (Loranthaceae). Journal of the Arnold Arboretum, 56, 265-335.
Kuijt, J. (2012). Reinstatement and Expansion of the genus Peristethium (Loranthaceae). Annals of the Missouri Botanical Garden, 98, 542-577.

Kuijt, J. (2013). Prophyll, calyculus, and perianth in Santalales. Blumea-Biodiversity, Evolution and Biogeography of Plants, 57, 248-252.

Kunth, K. S. (1820). Loranthanus leptostachyus. In F. W. H. A. von Humboldt, A. J. A. Bonpland, \& K. S. Kunth (Eds.), Nova Genera et Species Plantarum (vol. 3, p. 440). Paris: Librariæ Græco-Latino-Germanicæ.

Martius, K. F. P. (1830). Einige Bemerkungen über Loranthus. Flora, 13, 97-112.

Mathiasen, R., Nickrent, D., Shaw, D., \& Watson, D. (2008). Mistletoes: Pathology, Systematics, Ecology, and Management. Plant Disease, 92, 988-1006.

Nickrent, D., Malecot, V., Vidal, R., \& Der, J. (2010). A revised classification of Santalales. Taxon, 59, 538-558.

Ruzin, S. E. (1999). Plant microtechnique and microscopy. New York: Oxford University Press.

Simões, C., Gomes, K. M., \& Barnes, C. E. (2014). A new combination in Peristethium (Loranthaceae) expands the genus' range into the Amazon-Cerrado ecotone. Acta Amazonica, 44, 169-174.

Smart, C. (1952). The life history of Tupeia Cham. et Schl. (Loranthaceae). Transactions of the Royal Society of New Zealand, 79, 459-466.

The Plant List (2013). Version 1.1. Retrieved October 1, 2014, from http://www.theplantlist.org/1.1/ Browse/A/Loranthaceae.

Van-Tieghem, P. (1895). Sur le groupement des espéces dans les Loranthées à calice dialysépale et anthères oscilantes out Struthanthées. Bulletin de la Société Botanique de France, 42, 161-180.

Venturelli, M. (1981). Embriologia de Struthanthus vulgaris (Loranthaceae- Loranthoideae). Kurtziana, 14, 73-100.

Venturelli, M. (1983). Estudos embriológicos em Loranthaceae: gênero Tripodanthus. Kurtziana, 16, 71-90.

Venturelli, M. (1984a). Morfologia e anatomia floral de Struthanthus vulgaris Mart. (Loranthaceae). Revista Brasileira de Botânica, 7, 121-128.

Venturelli, M. (1984b). Estudos embriologicos em Loranthaceae: Struthanthus flexicaulis Mart. Revista Brasileira de Botânica, 7, 107-119.

Vidal, R., \& Nickrent, D. L. (2008). Evolutionary relationships in the showy mistletoe family (Loranthaceae). American Journal of Botany, 95, 1015-1029.

Wanntorp, L., \& De Craene, L. P. (2009). Perianth evolution in the sandalwood order Santalales. American Journal of Botany, 96, 1361-1371. 